\title{
Systemic contact dermatitis caused by cobalt chloride and palladium in a 26-year-old woman with allergic type I reactions, non-steroidal anti-inflammatory drug hypersensitivity and autoimmune thyroiditis
}

\author{
Bernard Panaszek, Daria Nowak, Katarzyna Cieślik, Paulina Dziemieszonek, Krzysztof Gomułka \\ Department of Internal Medicine and Allergology, Wroclaw Medical University, Wroclaw, Poland \\ Adv Dermatol Allergol 2017; XXXIV (4): 388-390 \\ DOI: https://doi.org/10.5114/ada.2017.69324
}

Skin reactions are different in pathogenesis, types and symptoms. They include contact dermatitis (CD), which could be caused by contact allergens, haptens mostly. They are a class of antigens of molecular weight below 500 Da [1]. Especially, many metals have the potential to trigger type IV of allergic reactions: nickel [2, 3], cobalt [4] or chrome [5] mainly. Furthermore, haptens are present in various chemical agents for example cosmetics [6]. In minority of cases some kinds of haptens are able to cause generalized skin reactions typical for CD after systemic administration, for example by oral route, inhalation or intramuscular injection [7]. Haptens responsible for causing systemic contact dermatitis (SCD) could be derived from the animal and vegetable world as a part of the human diet. Certain universally consumed types of food contain potent allergens like nickel, balsam of Peru, urushiol, and sesquiterpene lactones [8].

We describe a case of SCD in a patient presenting also an immediate type of allergic hypersensitivity, hypothyroidism in the course of autoimmune inflammation of the thyroid gland with hypersensitivity to non-steroidal anti-inflammatory drugs (NSAIDs).

A 26-year-old woman was admitted to the Department of Internal Diseases, Geriatrics and Allergology in 2014 because of suspected drug hypersensitivity. The clinical picture had a number of complicating features which, we felt, deserved broader explanation. First alarming symptoms appeared in the young woman 8 years prior to her referral to our clinic. There were eczematous skin lesions around eyes (Figure 1), temples and the neck, usually with accompanying severe headaches. Four years later, after she took ibuprofen, urticaria and angioedema occurred. It was manifested by swelling of lips, eyelids, and hives on the abdominal wall and on the back. More- over, there was an allergic eczema on her face. At the emergency room the appropriate treatment was implemented and all signs subsided. Since that time, various types of recurrent skin lesions typical for eczema on different parts of the body have occurred in the patient. They usually appeared on the hands and face, and less frequently on legs, arms, around knees, on elbows, but also on the abdominal wall, back and neck after consuming a meal containing cobalt and/or palladium (Figures 2, 3). Eczematous skin lesions in the neck were also associated with the use of synthetic jewelry by the patient. Furthermore, she presented numerous episodes of spontaneous recurrent urticaria. Skin eruptions typical for both contact dermatitis and urticaria were itchy. Another problem was chronic rhinitis during all year round. In addition, hypothyroidism in the course of autoimmune thyroiditis was diagnosed in the young woman a few months before presentation to our department.

Physical examination, at admission, showed no significant deviations from the norm. There were no changes in the skin. The patient had not taken antihistamines since one month by then. The results of basic laboratory tests were without irregularities, including: erythrocyte sedimentation rate (ESR) $4 \mathrm{~mm} / 1 \mathrm{~h}$, C-reactive protein (CRP) $0.3 \mathrm{mg} / \mathrm{l}$, rheumatoid factor (RF) under $10 \mathrm{lU} / \mathrm{ml}$. But it was a high titer of anti-thyroid peroxidase (TPO) antibodies (> 1,000 IU/ml). Anti-nuclear antibodies (ANA1, ANA2) were positive. Thyroid hormone levels were in the normal range, because the patient was taking levothyroxine as a substitute for the insufficient hormone production by the thyroid gland. Total serum IgE amounted to $12.3 \mathrm{lU} / \mathrm{ml}$. Skin prick testing showed a positive reaction to fur and skin of a cat, hazelnut and wheat flour $(3 / 3 \mathrm{~mm})$. The patch test read at $72 \mathrm{~h}$ gave

Address for correspondence: Krzysztof Gomułka MD, PhD, Department of Internal Medicine and Allergology, Wroclaw Medical University, 66 Marii Curie-Skłodowskiej St, 50-369 Wroclaw, Poland, phone: +48 7178425 28, e-mail: kgomulka@wp.pl Received: 2.11.2015, accepted: 4.10.2016. 


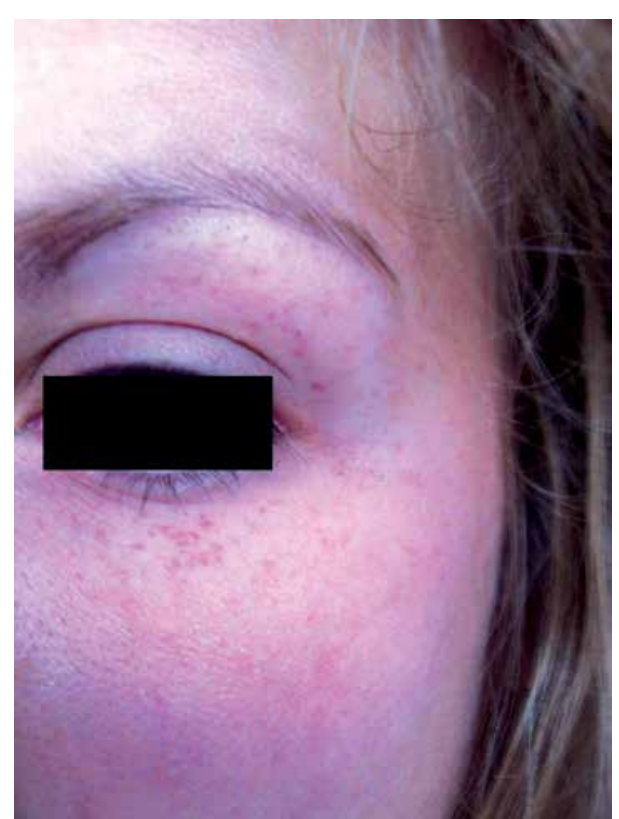

Figure 1. Eczematous skin lesions around eyes

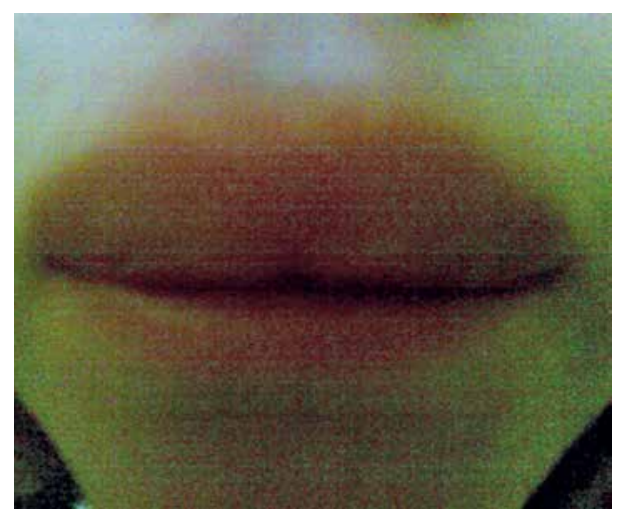

Figure 3. Angioedema occurred after taking ibuprofen by the patient

$(+++)$ positive reactions for cobalt chloride hexahydrate (1\% petrolatum) and (+) for palladium (Figure 4). Exposition physical tests were also carried out. Trial of pressure and ice cube test gave positive reactions, whereas an autologous serum assay was negative.

In the case presented here there is an unprecedented coincidence of many allergic diseases, depending on different types of immune response: I, III and IV according to Gell and Coombs classification [9].

Most of all, our patient demonstrated a positive reaction to metals, such as cobalt and palladium due to type IV hypersensitivity and the main role of Th1 lymphocytes. We assumed the reaction was of allergic origin because the persistent reaction of patch testing was observed and the possibility of irritant contact dermatitis was thus excluded [4]. Moreover, chronic rhinitis was

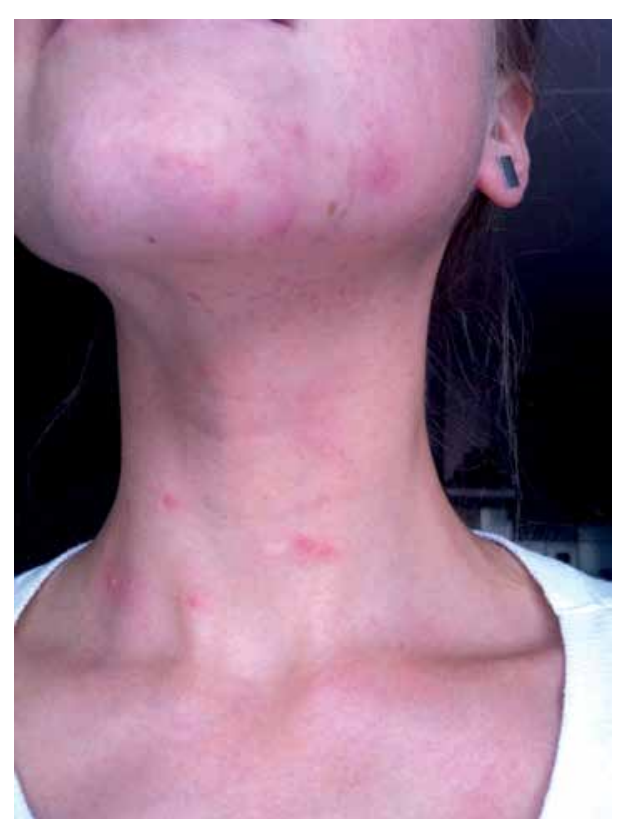

Figure 2. Generalized eczema usually appeared on face and neck after consuming meal containing cobalt and/or palladium

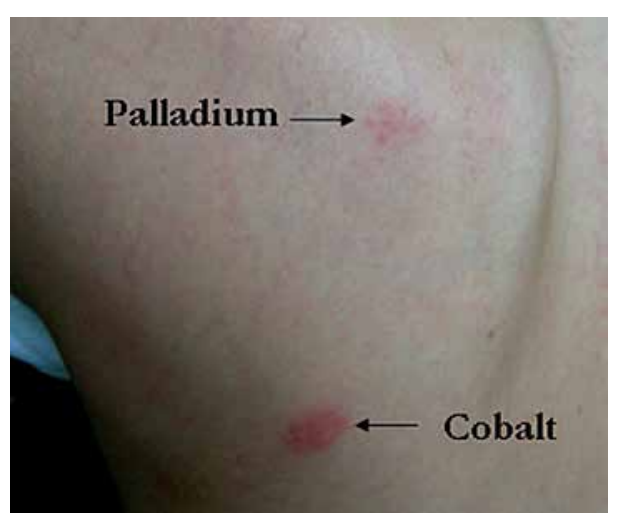

Figure 4. Patch test read at $72 \mathrm{~h}$ gave $(+++)$ positive reactions for cobalt chloride hexahydrate ( $1 \%$ petrolatum) and (+) for palladium

present, which indicates the occurrence of a mechanism typical for type I of immune reactions, confirmed by skin prick testing in which Th2 cells are participating [10]. It is well known that both Th1 and Th2 lymphocytes release quite a different profile of cytokines which are opposite to each other in the pathomechanism of allergic diseases [11]. Particularly fascinating is the co-occurrence of the autoimmune disease with a speculative link to sufficient numbers of self-reactive $T$ cells which can create an increased risk of the development of autoimmunity [12]. Coincidence of NSAIDs hypersensitivity, provoking, regardless of allergens, urticaria and angioedema seems to be an independent phenomenon in this case, caused both by immunological and biochemical reactions arising from inhibition of cyclooxygenase 1. Admittedly some researchers indicate a higher incidence of hypersensitivity 
to NSAIDs in allergic diseases, but the mechanism for this is doubtful [13].

The main treatment is avoiding direct contact with cobalt and palladium. It is important that the patient's nourishment must not contain cobalt [14]. Moreover, immediate discontinuation of wearing jewelry containing those metals is essential, too. Our patient has complied with these recommendations and has not reported skin manifestations like eczematous lesions anymore after leaving the hospital. Certainly full control of other chronic diseases, most of all allergic rhinitis (antihistamines and nasal steroids) and avoidance of NSAIDs, also contributed to a complete remission of systemic contact dermatitis. It is also important to substitute the insufficient hormone production by the thyroid gland but there is no clear evidence that levothyroxine contributes to complete remission of allergic symptoms.

Based on the clinical presentation, our case is a unique clinical phenotype, as we diagnosed systemic allergic contact dermatitis due to cobalt and palladium (type IV hypersensitivity), coexisting with allergic rhinitis caused by allergens such as fur and skin of animals and food allergens (type I reaction) and recurrent urticaria/ angioedema with hypersensitivity to NSAIDs. Additionally, occurrence of autoimmune thyroiditis (type III reaction) in this case enhances the difficulty in explaining one common link as present in this phenomenon, which however may exist. Emerging data that monomeric IgE may have a heterogeneous function as an autoreactive antibody also against self antigens in several immune reactions suggest a common link between allergic rhinitis, urticaria, autoimmune thyroiditis, NSAID hypersensitivity and possibly SCD [15]. It is noteworthy that, according to our knowledge, such comorbidity with several, different types of immune responses is a very rare phenomenon and unpublished so far.

\section{Conflict of interest}

The authors declare no conflict of interest.

\section{References}

1. Peiser M. Role of Th17 cells in skin inflammation of allergic contact dermatitis. Clin Dev Immunol 2013; 2013: 261037.

2. García-Rabasco AE, Zaragozá-Ninet V, García-Ruíz R, de la Cuadra-Oyanguren J. Allergic contact dermatitis due to nickel: descriptive study in a tertiary hospital, 2000-2010. Actas Dermosifiliogr 2014; 105: 590-6.

3. Wojciechowska M, Czajkowski R, Kowaliszyn B, et al. Analysis of skin patch test results and metalloproteinase-2 levels in a patient with contact dermatitis. Postep Derm Alergol 2015; 32: 154-61.

4. Arslan S, Aksan S, Ucar R, Caliskaner AZ. Contact dermatitis to cobalt chloride with an unusual mechanism. Prosthet Orthot Int 2015; 39: 419-21.

5. Carøe C, Andersen KE, Thyssen JP, Mortz CG. Fluctuations in the prevalence of chromate allergy in Denmark and ex- posure to chrome-tanned leather. Contact Dermatitis 2010; 63: 340-6.

6. Kumar P, Paulose R. Patch testing in suspected allergic contact dermatitis to cosmetics. Dermatol Res Pract 2014; 2014: 695387.

7. Kulberg A, Schliemann S, Elsner P. Contact dermatitis as a systemic disease. Clin Dermatol 2014; 32: 414-9.

8. Fabbro SK, Zirwas MJ. Systemic contact dermatitis to foods: nickel, BOP, and more. Curr Allergy Asthma Rep 2014; 14: 463.

9. Rajan TV. The Gell-Coombs classification of hypersensitivity reactions: a re-interpretation. Trends Immunol 2003; 24: 376-9.

10. Scadding G. Cytokine profiles in allergic rhinitis. Curr Allergy Asthma Rep 2014; 14: 435.

11. Zhang Y, Zhang Y, Gu W, et al. Th1/Th2 cell's function in immune system. Adv Exp Med Biol 2014; 841: 45-65.

12. Koehli S, Naeher D, Galati-Fournier V, et al. Optimal T-cell receptor affinity for inducing autoimmunity. Proc Natl Acad Sci USA 2014; 111: 17248-53.

13. Blanca-López N, Barrionuevo E, Andreu I, Canto MG. Hypersensitivity reactions to nonsteroidal anti-inflammatory drugs: from phenotyping to genotyping. Curr Opin Allergy Clin Immunol 2014; 14: 271-7.

14. De Marchi S, Cecchin E, De Marchi SU. Systemic allergic dermatitis resulting from oral administration of chromium with a food supplement. Contact Dermatitis 2014; 70: 123-5.

15. Chang TW, Chen C, Lin CJ, et al. The potential pharmacologic mechanisms of omalizumab in patients with chronic spontaneous urticaria. J Allergy Clin Immunol 2015; 135: 337-42. 